Yerbilimleri, 2019, 40 (2), 253-267, DOI:10.17824/yerbilimleri.557605

Hacettepe Üniversitesi Yerbilimleri Uygulama ve Araştırma Merkezi Bülteni

Bulletin of the Earth Sciences Application and Research Centre of Hacettepe University

\title{
Yozgat Yöresi Tüflerinin Çimento Katkısı Olarak Kullanılabilirliğinin İncelenmesi
}

\section{Investigation of Usability of Yozgat Region Tuffs as Cement Additives}

\section{ABDUL VAHAP KORKMAZ *1}

Afyon Kocatepe Üniversitesi, Endüstri Ürünleri Tasarımı Bölümü, 03200 Afyonkarahisar

ÖZ

Puzolanik özelliklere sahip birçok yapay ve doğal madde, çok eski zamanlardan günümüze kadar inşaat yapım alanında ve beton üretiminde çeşitli amaçlarla kullanılmışlardır. Bu maddeler betonun fiziksel, mekanik ve dayanım (durabilite) özelliklerini iyileştirmek ve üretim maliyetini önemli ölçüde düşürmeleri nedeniyle de tercih edilmektedirler. Bu çalışmada Yozgat tüflerinin puzolanik çimentolarda değişik oranlarda ikameli olarak kullanılmasının beton performansına etkisi araştırılmıştır. Bu sayede Yozgat bölgesindeki bakir tüf sahalarının ekonomiye kazandırılıp bölge için önemli katkılar sağlanması düşünülmüştür. Yozgat yöresine ait 4 farklı sahadan alınan volkanik kayaç örnekleri ile üretilen puzolanik çimentolar kimyasal, fiziksel, mekanik testler ile hidratasyon Isısı ve kızdırma kaybı analizlerine tabi tutulmuşlardır. Portland çimentosu klinkeri $\% 20$ ve $\% 40$ oranında sırası ile tüf örnekleri ile ikame edilmiştir. Kimyasal ve mineralojik analiz sonuçları malzemenin $\mathrm{SiO}_{2}+\mathrm{Al}_{2} \mathrm{O}_{3}+\mathrm{Fe}_{2} \mathrm{O}_{3}$ toplam içeriği \% 77,97-82,25 arasında değişen volkanik kökenli porfirik trakiandezit olduğunu göstermiştir. Yozgat yöresi volkanik kayaç örneklerinin puzolanik aktiviteleri 6,3-10,7 MPa arasında değişen basınç dayanımları tespit edilmiş aynı zamanda bu değerlerin oksit oranlarıyla ilişkisi ortaya konulmuştur. Yozgat yöresine ait tüf örneklerinin reaktif silis ve puzolanik aktivite test sonuçları TS EN 197-1 ve TS 25'e göre tras kriterlerine uymaktadır. Puzolanik çimento üretiminde tras oranının \%20'den \% 40'a yükseltilmesi çimento örneklerinin erken yaştaki dayanımını azaltmış, 28 günlük dayanımları ise standartlar değerler arasında kalmıştır. Yozgat tüflerinin Cem IV/B puzolanik çimentolarda \% 40’a kadar kullanılabilecekleri sonucuna varılmıştır.

Anahtar Kelimeler: Katkılı çimento, tras, tüf, Yozgat, çimento dayanımı.

https://doi.org/10.17824/yerbilimleri.557605

Abdul Vahap KORKMAZ avkorkmaz@aku.edu.tr

\footnotetext{
${ }^{1}$ Afyon Kocatepe Üniversitesi, Endüstri Ürünleri Tasarımı Bölümü, 03200 Afyonkarahisar, ORCıD 0000-0001-8691-1937
} 


\section{ABSTRACT}

Many artificial and natural materials with pozzolanic characteristics have been used for many different purposes in construction field and in concrete production for many years. They are also preferred because they improve the physical, mechanical and durability properties of concrete and significantly reduce the cost of production. In this study, the effect of different proportions of Yozgat tuff on pozzolanic concrete and cement performance was investigated. In this way, it is thought that the untrodden tuff reserves in the Yozgat region will be added to the economy and important contributions will be made for the region. Chemical, physical, mechanical analyzes and hydration heat and ignition loss analyzes were performed with the pozzolanic cements produced from the volcanic rock samples taken from 4 different areas of the Yozgat region. Portland cement clinker is substituted with $20 \%$ and $40 \%$ of tuff samples respectively. The results of the analysis showed that the material was porous trachyandesite with a volcanic origin of $\mathrm{SiO}_{2}+\mathrm{Al}_{2} \mathrm{O}_{3}+\mathrm{Fe}_{2} \mathrm{O}_{3}$ with a total content of $77,97-82,25 \%$. The pozzolanic activities of the volcanic rock samples in the Yozgat region were determined to have compressive strengths ranging from 6.3-10.7 MPa. Increasing the ratio of trass from $20 \%$ to $40 \%$ in cement production decreased the early strength of cement samples and 28 days durations remained between the values. Reactive silica and pozzolanic activity test results of the tuff samples of the Yozgat region meet the trass criteria according to TS EN 197-1 and TS 25. It has been concluded that Yozgat tuffs can be used up to 40\% in Cem IV /B pozzolanic cements.

Keywords: Cement additive, trass, tuff, Yozgat, cement strength.

\section{GíRiş}

Portland çimentosu klinkeri üretildikten sonra, hem çimento maliyetini düşürerek üretimi artırmak hem de değişik çimento cinsleri üretmek için klinkere belirli oranlarda katkı maddeleri katılmaktadır. Bu katkı maddeleri puzolanik aktiviteye sahip olan tras, uçucu kül, pomza ve yüksek fırın cürufu gibi doğal veya yapay malzemelerdir. Belirli oranlarda katkı maddeleri kullanılarak, üretilen çimentolar özelliklerinden bir şey kaybetmedikleri gibi kalitesinde de en ufak bir değişiklik meydana gelmemektedir. Hatta puzolanik katkıı çimentolar kullanım yerlerine göre, bazı üstün mekanik özellikler kazanmaktadırlar (Postacıoğlu vd., 1960). 
Doğal puzolanlar, genellikle çimento yapısına uygun kimyasal ve mineralojik bileşimli volkanik kökenli malzemeler veya tortul kayalardır. Volkanik küllerin bünyesinde olduğu gibi içerisinde silis ve alümin bulunduran, söndürülmüş kireç ve su ile normal sıcaklıkta birleştiğinde, bağlayıcılık özelliği kazanan bütün maddelere genel bir isim verilerek 'Puzolan' ve bu özelliğe de 'Puzolanik aktivite 'denilmektedir. Ülkemiz puzolanik özelliklere sahip oldukça zengin maden yataklarına sahiptir. Bunlara tras ve pomza örnek verilebilir. Tras silisli ve alüminli mineralleri içeren volkanik bir tüftür (Binici, 2002).

Puzolanik katkılı çimento üretiminde bir çeşit katkı kullanılabildiği gibi birden fazla katkı maddesi de kullanılabilir. Çimentolar, kullanılan katkı oranlarına ve bazen de katkı çeşitlerine göre de adlandırılırlar. Bazı ülke standartları Cem IV/B puzolanik katkılı çimentoda \%36-55 arasında kalker ve puzolanik malzemelere izin verdiği gibi toplam katkı sınırını geçmemek kaydı ile \%0-5 arasında minör ilave katkıya izin vermektedir ( Kaya, 2010). Yüksek puzolanik özelliklere sahip traslar \%40’tan \% 90'a kadar $\mathrm{SiO}_{2}$ içerebilirler. Puzolanik katkılı çimentolarda kireç $(\mathrm{CaO})$ içeriği genelde çok düşük, fakat alkaliler $\left(\mathrm{Na}_{2} \mathrm{O}, \mathrm{K}_{2} \mathrm{O}\right)$ dikkate değer miktarda bulunurlar (Korkmaz, 2017).

\section{Puzolanik Kayaçların Çimento Performans Özellikleri}

Yoğunluk, tane şekli, incelik ve gözeneklilik gibi kriterler puzolanik aktivite ile yakından ilişkilidir. Puzolanik özelliğe sahip malzemeler 2,3 ila $2,8 \mathrm{~g} / \mathrm{cm}^{3}$ arasında değişen yoğunluklara sahiptir. Puzolanik malzemeler keskin köşeler, çok yüksek gözeneklilik, çok ince bir tane yapısına ve fazla su tutma yeteneğine sahiptirler. Bu fiziksel ve kimyasal özelliklerin tümü, sertleşmiş betonun farklı özelliklerini etkileyen en önemli faktörlerden olan uygulama olanaklarını ve tatlı su ihtiyacını etkilemektedir (Heikal vd., 2000). Puzolanik çimentolu betonlar, tekabül ettikleri Portland çimentolu betonlara göre, kimyasal maddelere karşı daha dayanıklıdır. Çünkü puzolanik çimentolu betonların porozite ve geçirgenlikleri daha az yani daha sıkı betonlardır. Ayrıca betonun içinde kimyasal madde ile reaksiyona girecek metal oksidi hemen hemen kalmamıştır, kalanlar ise katkının aktif silikatlarıyla bileşik oluşturmuştur. Bu da yerine göre betonun ömrünü arttırmaktadır (Hewlett, 1998).

Kavas ve Çelik (2001), Ayazini tüflerinin katkılı Portland çimentosu üretiminde (KPÇ) katkı maddesi olarak kullanılmasını araştırmış ve üretilen tüf katkılı çimento örneklerine yapılan basınç dayanımları 5,7-10,6 N/mm² arasında değişirken, eğilmede çekme dayanımları 1,4$2,5 \mathrm{~N} / \mathrm{mm}^{2}$ olarak bulmuştur. Yapılan testler sonucunda Ayazini bölgesinde bulunan tüflerin katkılı çimento üretiminde tras olarak kullanılabileceği görülmüştür. 
Alp vd. (2004) Taşhane andezitik tüflerinin katkılı çimento üretiminde katkı malzemesi olarak kullanılabilirliğini araştırmıştır. Portland çimento klinkeri ile farklı oranlarda katkılı olarak yapılan puzolanik aktivite test sonuçları, Taşhane traslarının TS 197-1'de belirtilen traslı çimento özelliklerine uygun katkılı çimento üretiminde \%27 oranına kadar katkı malzemesi olarak kullanılabileceğini göstermiştir. Taşhane trasları, TS 12143 standartlarına göre \%20' den daha az oranlarda tras içeren PKÇ/A sınıfı 32,5R tipi veya \%20-30 oranlarında tras içeren PKÇ/B sınıfı 32,5R tipi çimento üretimine uygun olduğu görülmüştür.

Kavas ve Çelik (2001), Ayazini tüfleri ile ilgili çalışmada 16 adet örnek ile çalışılmış olup Tüf örneklerinin tras standartlarına uygunlukları araştırılmıştır. Fakat Tüf örnekleri ile Puzolanik bir çimento üretilmemiş ve kalite standartları araştırılmamıştır.

Taşhane andezitik tüfleri ile ilgili çalışmada tek bir örnek üzerinden gidilerek \% 35' e kadar katkı kullanılmıştır (Alp vd., 2004). En uygun tüf katkısının \% 27 oranında olduğuna karar verilmiştir.

Yozgat tüfleri ile ilgili yapılan mevcut çalışmada yukarıda bahsedilen çalışmalardan farklı olarak Yozgat yöresine ait 4 farklı tüf örneği ile \% 20 ve \% 40 tüf katkısı ile 4 farklı puzolanik çimento üretilmiştir. Çimento dayanımı ve kalite standartları doğrultusunda karşılaştırmalar yapılmış ve Tüf1 ve Tüf4 için \% 40 tüf katkısı ile Cem IV/B(P) 32,5R çimentosu üretilebileceği görülmüştür.

\section{MATERYAL VE METOT}

\section{Materyal}

Doğal puzolan örnekleri, Yozgat iline bağlı, Akdağ madeni, Çekerek, Kadışehri ve Saraykent ilçelerinde bulunan tras sahalarından alınmıştır. Çekerek ve Kadışehri formasyonlarında masif, koyu renkli, demirce zengin biyotit ve kısa kalın kristaller halinde bulunan koyu renkli piroksen mineralleri içeren andezitik kökenli tüf seviyelerine rastlanılmıştır. Masif tras tabakaları, ortalama 50-100 cm yükseklikte, volkanik kayaçların eteklerinde $300-500 \mathrm{~cm}$ kalınlığına ulaşan, açık kahverengi çakıllı kil niteliğindeki molozlar ile yüzeyi örtülmüştür. Akdağ madeni ve Saraykent çalışma sahasında ise camsı faz miktarı yüksek albit, kristobalit ve alkali feldspat miktarı yüksek, kil mineralleri (montmorillonit) ise düşük, puzolanik özelliği yüksek tras formasyonları gözlenmiştir. Yozgat tüflerinin yüzeyi 60-80 cm kalınlığında çakıllı kil karışımı niteliğindeki kahve renkli toprak zemin ile örtülü olduğu görülmüştür. 
Çalışma sahasında bulunan trasların bölgedeki tabakalı kaya dizilimleri saptanarak konumları ve sınırları tespit edilmiş, renk ve homojenite gibi bir takım saha makroskopik özellikleri belirlenmiştir (Şekil 1).

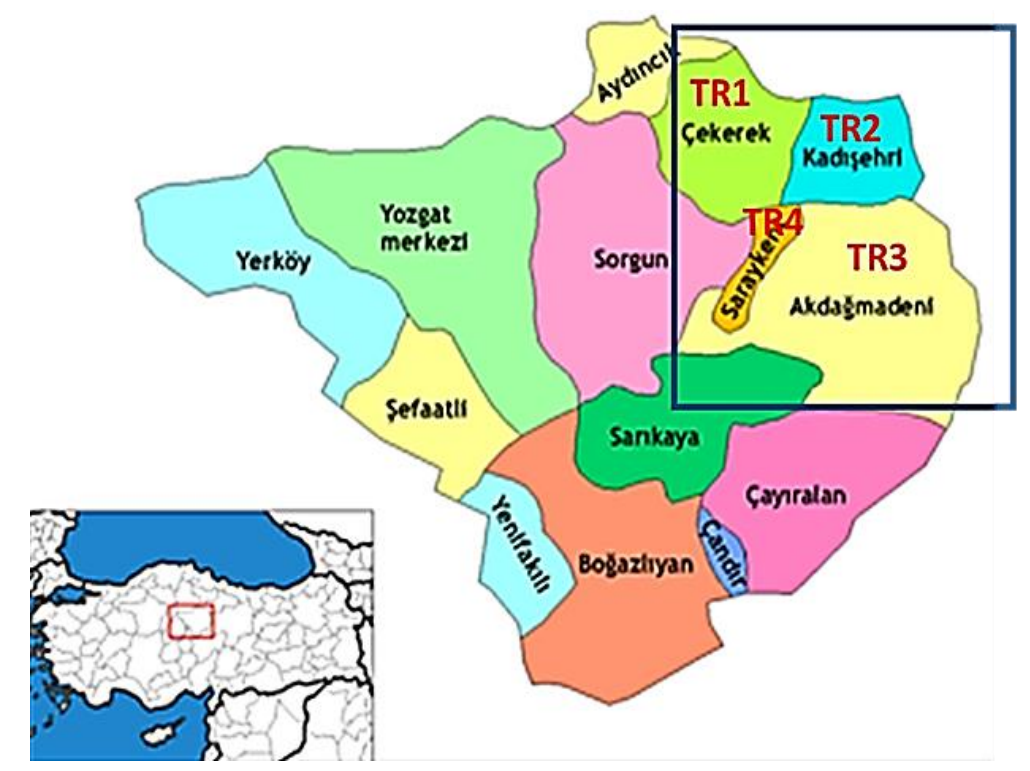

Şekil 1. Çalışma alanının yer bulduru haritası (TR: Tras).

Figure 1. Location map of the study area (TR: Trass).

\section{Yozgat tüflerinin kimyasal ve mineralojik olarak İncelenmesi}

Yozgat iline bağı 4 farklı lokasyondan alınan tüf örneklerine ait kimyasal analiz sonuçları Çizelge 1'de verilmiştir. Puzolanik çimento (Cem II-IV/B) üretiminde kullanılacak tüflerin uygunluk kriterleri TS 25 ve TS 197-1' de belirtilmiştir. Puzolanik çimento üretimi için kullanılabilecek tüf örneklerinin TS 25 'e göre kimyasal özelliklerinde bir takım sınırlamalar mevcuttur. $\mathrm{Bu}$ nedenle tüflerde istenen \% içerikleri $\left(\mathrm{SiO}_{2}+\mathrm{Al}_{2} \mathrm{O}_{3}+\mathrm{Fe}_{2} \mathrm{O}_{3}, \mathrm{MgO}\right.$ ve $\left.\mathrm{SO}_{3}\right)$ Çizelge 2' de verilmiştir. Illk olarak TS 25' e göre bir tüf örneğinin $\mathrm{SiO}_{2}+\mathrm{Al}_{2} \mathrm{O}_{3}+\mathrm{Fe}_{2} \mathrm{O}_{3}$ toplam değerinin en az \% 70 olması gerekmektedir (Mazsazza, 1989). Yozgat tüf örnekleri, TS 25'de açıklanan kimyasal komponentler ile karşılaştırıldığında, her bir tras örneğinin standartta yer alan değerleri sağladığı görülmektedir (Çizelge 2). Yozgat yöresine ait 4 farklı tüf örneği harmanlanarak kompozit bir numune haline getirilmiş ve kalitatif faz analizi (XRD) Esan kalite kontrol laboratuvarında gerçekleştirilmiştir. Panalytical Empyrian XRD cihazı ile Cu X-Isını tüpü (=1,5405 angstrom) kullanılarak mineralojik analizi yapılmış ve analiz sonucunda, kompozit tüf örneğinde amorf yapı gösteren bileşikler saptanmıştır. Yozgat tüfünde yapılan incelemeler neticesinde kuvars $\left(\mathrm{SiO}_{2}\right)$, feldspat, albit, az miktarda kristobalit $\left(\mathrm{SiO}_{2}\right)$ ve amorf yapı gösteren bileşiklerin olduğu görülmüştür. 
Çizelge 1. Tüf örneklerinin kimyasal analiz sonuçları.

Table 1. Chemical analysis results of tuff samples.

\begin{tabular}{ccccc}
\hline \multirow{2}{*}{ Içerik } & TR1 & TR2 & TR3 & TR4 \\
\cline { 2 - 5 } & $\%$ & $\%$ & $\%$ & $\%$ \\
\hline $\mathrm{SiO}_{2}$ & 68,38 & 66,1 & 64,41 & 66,81 \\
$\mathrm{Al}_{2} \mathrm{O}_{3}$ & 12,69 & 10,92 & 13,23 & 13,11 \\
$\mathrm{Fe}_{2} \mathrm{O}_{3}$ & 1,18 & 0,95 & 5,98 & 1,64 \\
$\mathrm{CaO}$ & 4,18 & 7,58 & 3,74 & 2,92 \\
$\mathrm{MgO}$ & 1,07 & 1,61 & 1,85 & 2,2 \\
$\mathrm{Na}_{2} \mathrm{O}$ & 0,02 & 0,13 & 0,02 & 0,13 \\
$\mathrm{~K}_{2} \mathrm{O}$ & 3 & 2,58 & 2,27 & 2,87 \\
$\mathrm{SO}_{3}$ & 0,19 & 0,09 & 0,15 & 0,06 \\
$\mathrm{TiO}_{2}$ & 0,16 & 0,02 & 0,24 & 0,03 \\
$\mathrm{P}_{2} \mathrm{O}_{5}$ & 0,02 & 0,02 & 0,05 & 0,03 \\
$\mathrm{~K} . \mathrm{K}$ & 8,7 & 9,54 & 7,45 & 9,57 \\
$\mathrm{Toplam}$ & 99,59 & 99,55 & 99,42 & 99,43 \\
\hline
\end{tabular}

Çizelge 2. TS 25' e göre tüf örneklerinin uygunluk kriterleri.

Table 2. Compliance criteria of tuff samples according to TS 25.

\begin{tabular}{lccccc}
\hline \multirow{2}{*}{ İcrik } & TS 25 & TR1 & TR2 & TR3 & TR4 \\
\cline { 2 - 6 } & $\%$ & $\%$ & $\%$ & $\%$ & $\%$ \\
\hline $\mathrm{SiO}_{2}+\mathrm{Al}_{2} \mathrm{O}_{3}+\mathrm{Fe}_{2} \mathrm{O}_{3}$ & $\geq 70$ & 82,25 & 77,97 & 83,62 & 81,56 \\
$\mathrm{MgO}$ & $\leq 5$ & 1,07 & 1,61 & 1,85 & 2,2 \\
$\mathrm{SO}_{3}$ & $\leq 3$ & 0,19 & 0,09 & 0,15 & 0,06 \\
Rutubet & $\leq 10$ & 5 & 6,5 & 8,2 & 6,2 \\
\hline
\end{tabular}

Klinker örneği alınan çimento fabrikasında klinker üretimi için \% 20,41 oranında çimento kili, $\% 78,20$ oranında kalker ve \%1,39 oranında demir cevheri kullanılmaktadır. Entegre çimento üretiminde kullanılan ham maddelerin kimyasal bileşimleri Çizelge 3' te verilmiştir. Klinker örneği, Yozgat yöresine ait tüf örnekleri ve alçıtaşı ile farkıı oranlarda karıştırıldıktan sonra laboratuvar ölçekli çelik bilyeli değirmende $35 \mathrm{dk}$ öğütülmüştür. Karışım oranları ve miktarları Çizelge 4' te özetlenmiştir. Çimento karışımında kullanılan alçıtaşı $\% 40,5$ SO3 ve \%17,8 $\mathrm{H} 2 \mathrm{O}$ içermektedir. Öğütme sonrasında elde edilen farklı tüf içeriklerine sahip puzolanik çimentoların kimyasal analizleri Çizelge 5' de verilmiştir. 
Çizelge 3. Çimento üretiminde kullanılan ham maddelerin kimyasal analiz sonuçları.

Table 3. Chemical analysis results of raw materials used in cement production.

\begin{tabular}{ccccc}
\hline \multirow{2}{*}{ İçerik } & Klinker & Kalker & Kil taşı & Demir cevheri \\
\cline { 2 - 5 } & $\%$ & $\%$ & $\%$ & $\%$ \\
\hline $\mathrm{SiO}_{2}$ & 21,00 & 0,24 & 58,83 & 21,6 \\
$\mathrm{Al}_{2} \mathrm{O}_{3}$ & 5,21 & 0,07 & 16,44 & 2,67 \\
$\mathrm{Fe}_{2} \mathrm{O}_{3}$ & 3,89 & 0,05 & 7,58 & 65,12 \\
$\mathrm{CaO}$ & 65,43 & 55,45 & 1,01 & 1,17 \\
$\mathrm{MgO}$ & 1,06 & 0,49 & 3,08 & 2,49 \\
$\mathrm{SO}$ & 0,43 & $<0,01$ & 0,17 & $<0,01$ \\
$\mathrm{Na}_{2} \mathrm{O}$ & 1,26 & $<0,01$ & 1,3 & $<0,01$ \\
$\mathrm{~K}_{2} \mathrm{O}$ & 0,97 & 0 & 3,46 & 0 \\
$\mathrm{TiO}_{2}$ & 0,01 & 0 & 0,65 & 0 \\
$\mathrm{P}_{2} \mathrm{O}_{5}$ & 0,02 & 0 & 0,12 & 0 \\
$\mathrm{KK}$ & 0,28 & 43,68 & 6,84 & 6,68 \\
$\mathrm{Toplam}$ & 99,57 & 99,98 & 99,6 & 99,73 \\
\hline
\end{tabular}

Çizelge 4. Puzolanik çimento üretiminde kullanılan tüf miktar ve oranları.

Table 4. Amount and rates of tuff used in pozzolanic cement production.

\begin{tabular}{|c|c|c|c|c|c|c|c|c|c|}
\hline \multirow{2}{*}{ TR1 } & \multicolumn{2}{|c|}{$\% 20$ Tüf } & \multicolumn{2}{|c|}{ \% 40 Tüf } & \multirow{2}{*}{ TR2 } & \multicolumn{2}{|c|}{$\% 20$ Tüf } & \multicolumn{2}{|c|}{ \% 40 Tüf } \\
\hline & Miktar(g) & $\%$ & Miktar(g) & $\%$ & & Miktar(g) & $\%$ & Miktar(g) & $\%$ \\
\hline Klinker & 3040 & 76 & 2240 & 56 & Klinker & 3040 & 76 & 2240 & 56 \\
\hline Tüf & 800 & 20 & 1600 & 40 & Tüf & 800 & 20 & 1600 & 40 \\
\hline Alçı & 160 & 4 & 160 & 4 & Alçı & 160 & 4 & 160 & 4 \\
\hline Toplam & 4000 & 100 & 4000 & 100 & Toplam & 4000 & 100 & 4000 & 100 \\
\hline \multirow{2}{*}{ TR3 } & \multicolumn{2}{|c|}{ \% 20 Tüf } & \multicolumn{2}{|c|}{ \% 40 Tüf } & \multirow{2}{*}{ TR4 } & \multicolumn{2}{|c|}{ \% 20 Tüf } & \multicolumn{2}{|c|}{ \% 40 Tüf } \\
\hline & $\operatorname{Miktar}(\mathrm{g})$ & $\%$ & Miktar(g) & $\%$ & & Miktar(g) & $\%$ & Miktar(g) & $\%$ \\
\hline Klinker & 3040 & 76 & 2240 & 56 & Klinker & 3040 & 76 & 2240 & 56 \\
\hline Tüf & 800 & 20 & 1600 & 40 & Tüf & 800 & 20 & 1600 & 40 \\
\hline Alçı & 160 & 4 & 160 & 4 & Alçı & 160 & 4 & 160 & 4 \\
\hline Toplam & 4000 & 100 & 4000 & 100 & Toplam & 4000 & 100 & 4000 & 100 \\
\hline
\end{tabular}


Çizelge 5. Hazırlanan puzolanik çimento örneklerinin kimyasal analiz sonuçları.

Table 5. Chemical analysis results of prepared pozzolanic cement samples.

\begin{tabular}{|c|c|c|c|c|c|c|c|c|c|c|}
\hline \multirow{2}{*}{ İçerik } & \multirow{2}{*}{ Klinker } & \multicolumn{2}{|c|}{ TR1 } & \multicolumn{2}{|c|}{ TR2 } & \multicolumn{2}{|c|}{ TR3 } & \multicolumn{2}{|c|}{ TR4 } & \multirow{2}{*}{$\begin{array}{l}\text { TS } \\
197-1\end{array}$} \\
\hline & & $\% 20$ & $\% 40$ & \%20 & $\% 40$ & $\% 20$ & $\% 40$ & \%20 & $\% 40$ & \\
\hline $\begin{array}{l}\text { Çözünmez } \\
\text { Kalıntı }\end{array}$ & & 15,56 & 28,12 & 16,13 & 27,34 & 16,56 & 29,12 & 15,13 & 28,34 & \\
\hline $\mathrm{SiO}_{2}$ & 20,84 & 29,51 & 39,02 & 29,06 & 38,11 & 28,72 & 37,43 & 29,20 & 38,39 & \\
\hline $\mathrm{Al}_{2} \mathrm{O}_{3}$ & 5,14 & 6,44 & 7,95 & 6,09 & 7,25 & 6,55 & 8,17 & 6,53 & 8,12 & \\
\hline $\mathrm{Fe}_{2} \mathrm{O}_{3}$ & 3,82 & 3,14 & 2,61 & 3,09 & 2,52 & 4,10 & 4,53 & 3,23 & 2,80 & \\
\hline $\mathrm{CaO}$ & 66,75 & 51,57 & 42,05 & 53,25 & 43,41 & 51,48 & 42,88 & 51,31 & 42,55 & \\
\hline $\mathrm{MgO}$ & 1,32 & 1,22 & 1,17 & 1,33 & 1,38 & 1,65 & 1,48 & 1,44 & 1,62 & $\leq 5$ \\
\hline $\mathrm{SO}_{3}$ & 0,62 & 0,51 & 0,42 & 0,49 & 0,38 & 0,50 & 0,41 & 0,48 & 0,37 & $\leq 3,5$ \\
\hline $\mathrm{Na}_{2} \mathrm{O}$ & 0,38 & 0,29 & 0,22 & 0,31 & 0,26 & 0,29 & 0,22 & 0,31 & 0,26 & \\
\hline $\mathrm{K}_{2} \mathrm{O}$ & 0,76 & 1,18 & 1,63 & 1,09 & 1,46 & 1,30 & 1,33 & 1,15 & 1,57 & \\
\hline $\begin{array}{l}\text { Kızdırma } \\
\text { Kaybı }\end{array}$ & 0,28 & 5,28 & 4,1 & 4,66 & 4,76 & 4,65 & 3,22 & 4,34 & 3,66 & $\leq 5$ \\
\hline Toplam & 99,91 & 99,14 & 99,18 & 99,37 & 99,54 & 99,24 & 99,67 & 98,01 & 99,35 & \\
\hline $\begin{array}{l}\text { Serbest } \\
\mathrm{CaO}\end{array}$ & 2,08 & 1,58 & 1,16 & 1,45 & 1,25 & 1,5 & 1,08 & 1,55 & 1,25 & \\
\hline
\end{tabular}

Metot

Andezitik tüf örneklerinin yoğunlukları TS EN 197-1, 2012'ye göre ve özgül yüzey (blaine) TS EN 196-6, 2010' ya göre hesaplanmıştır. Andezitik tüflerin kimyasal bileşimini belirlemek için X-Işınları floresans (XRF) ( Panalytical Axios ) analizi yapılmıştır. Andezitik tüflerin puzolanik aktivitelerinin belirleme yöntemi, TS 25'e göre, kireç-puzolan harçların basınç dayanımları ile belirlenen mekanik deney yöntemidir. Normal kıvam suyu ihtiyacı, priz süresi ve hacim sabitliği testleri, farklı oranlarda (\%20 ve \%40) andezitik tüf içeren puzolanik çimentoların ve Portland çimentosunun normal kıvam su ihtiyacı ve priz süreleri vikat cihazı ile hacim genleşmesi deneyleri ise Le Chatelier deney seti ile TS EN 196-3, 2017 standardına uygun olarak gerçekleştirilmiştir.

\section{Puzolanik aktivite deneyleri ve numunelerin hazırlanışı}

Herhangi bir malzemenin puzolanik özelliğe sahip olduğunu anlamak için puzolanik aktivite deneyinin yapılması gerekmektedir. Puzolanik aktivite deneyleri mekanik olarak puzolan çimento harçları üzerinde yapılan eğilme ve basınç dayanımı deneyleridir. Bu çalışmada TS 25'e göre yapılan aktivite deneyleri için kütlece \% 60-80 Portland çimentosu + \% 20-40 puzolanik malzeme kullanılarak farklı tipte çimento örnekleri hazırlanmış, örnekler üzerinde deneyler yapılarak puzolanların aktivitesi belirlenmiştir. 
TS 25'e göre hesaplanan malzeme miktarları ile puzolanlı harç numuneleri hazırlanmış ve harç numunelerine ait kalıpların üstü buharlaşmayı önleyecek şekilde temiz bir cam plaka ile kapatılmıştır. Puzolanlı harç numuneleri 24 saat $(23 \pm 2)^{\circ} \mathrm{C}$ ' lik oda sıcaklığında bekletildikten sonra numunelerin kalıpları sökülmeden $(55 \pm 2)^{\circ} \mathrm{C}$ sıcaklıktaki bir etüv içerisinde 6 gün daha bekletilmiştir. Puzolanlı harç numuneleri etüvden çıkartılarak oda sıcaklığına gelinceye kadar soğumaya bırakılmış ve TS EN 196-1, 2016'ya göre basınç dayanımı testlerine tabi tutulmuştur (Erdoğan, 2003).

Puzolanik aktivite, "aktivite indeksi" hesabı:

Dayanım aktivite indeksi $=(A / B) \times 100$

A: Puzolanik harcın ortalama basınç dayanımı,

B: Kontrol harcın ortalama basınç dayanımı

\section{Çimento deneyleri ve numunelerin hazırlanışı}

Andezitik tüflerin farklı (\%20 ve \%40) oranlarda Portland çimentosu ile yer değiştirilerek elde edilen puzolanik çimento numuneleri üzerinde normal kıvam suyu ihtiyacı, çimento harcı priz başlangıç ve bitiş süreleri ve hacim genleşmesi deneyleri TS EN 196-3, 2017 standardına uygun olarak gerçekleştirilmiştir.

\section{Ham maddelerin kızdırma kaybı tayini}

Sabit tartıma getirilmiş krozeye, rutubeti alınmış çimento numunesinden 0,0001 hassasiyetle $1,00 \mathrm{~g}(\mathrm{~m} 1)$ alınmıştır. $975^{\circ} \mathrm{C} \pm 25^{\circ} \mathrm{C}$ sıcaklıktaki fırında 15 dakika kızdırılmıştır. Desikatörde oda sıcaklığına kadar soğutulmuş ve tartılmıştır. Yeniden 5 dakika kızdırılarak oda sıcaklığına kadar soğutulup tekrar tartılmıştır. Bu işleme sabit tartıma (m2) ulaşıncaya kadar devam edilmiştir (TS EN 196-2, 2014).

Hesaplama:

Kızdırma kaybı $==\left[\frac{\mathrm{m} 1-\mathrm{m} 2}{\mathrm{~m} 1}\right] \times 1000$

m1: Deney numunesi kütlesi ( $\mathrm{g}$ )

m2: Kızdırılmış deney numunesinin sabit tartıma geldikten sonraki kütlesi (g)

\section{BULGULAR VE TARTIŞMA}

\section{Tüf Örneklerinin Fiziksel Ve Mekanik Özellikleri}

Puzolanik özelliğin tespiti için kullanılan mekanik testler, kireç veya çimentoyla karıştırılanpuzolanlarla üretilen harç örneklerinin basınç ve eğilme dayanımları saptanarak 
puzolanların aktif silise sahip olup olmadıkları belirlenir. Bu test metodu puzolanik özelliklerinin belirlenmesinde bir malzemenin reaksiyona girme ve bağlayıcı ürünler oluşturma gibi özelliklerin ortaya çıkarılmasında yaygın olarak başvurulan bir yöntemdir. Üretilen harç ve betonun kimyasal ortalama dayanıklıı̆ı puzolanların aktif silis miktarına bağlı olarak yükselir. (Erdoğdu vd., 1999). Fiziksel bulgular ve puzolanik aktivite deneyleri sonuçları dört farklı Yozgat tüf örneğinin TS 25'te açıklanan standart değerlere uygun olduğunu göstermiş olup örneklerin test sonuçları Çizelge 6' da verilmiştir. Puzolanik harç örneklerinin TS 25'de istenen minimum çekme ve basınç dayanımı değerlerini karşıladığı sırasıyla görülmektedir.

Çizelge 6. Fiziksel özellikler ve puzolanik aktivite test sonuçları (7 gün, TS 25).

Table 6. Physical properties and pozzolanic activity test results (7 days, TS 25).

\begin{tabular}{|c|c|c|c|c|c|}
\hline Deneyler & Birim & TR1 & TR2 & TR3 & TR4 \\
\hline Basınç dayanımı & $\left(\mathrm{N} / \mathrm{mm}^{2}\right)$ & 10,70 & 6,30 & 7,60 & 10,10 \\
\hline Çekme dayanımı & $\left(\mathrm{N} / \mathrm{mm}^{2}\right)$ & 3,40 & 2,70 & 2,40 & 3,0 \\
\hline Yoğunluk & $\left(\mathrm{g} / \mathrm{cm}^{3}\right)$ & 2,58 & 2,71 & 2,62 & 2,65 \\
\hline Özgül yüzey & $\left(\mathrm{cm}^{2} / \mathrm{gr}\right)$ & 4928 & 4865 & 4890 & 4924 \\
\hline $45 \mu \mathrm{m}$ elek üstü & $\%$ & 4,80 & 5,10 & 6,0 & 5,60 \\
\hline $90 \mu \mathrm{m}$ elek üstü & $\%$ & 1,80 & 1,90 & 1,90 & 1,80 \\
\hline D.Y.K. özgül ağırlık & & 2,10 & 2,10 & 2,10 & 2,10 \\
\hline Kuru özgül ağırlık & & 1,90 & 1,90 & 1,90 & 1,90 \\
\hline Zahiri özgül ağırlık & & 2,37 & 2,37 & 2,37 & 2,37 \\
\hline Don dayanıksızlığı & $\%$ & 2,93 & 2,93 & 2,93 & 2,93 \\
\hline Absorbsiyon nispeti & $\%$ & 13,25 & 13,25 & 13,25 & 13,25 \\
\hline Birim hacim ağırlığı & $\mathrm{g} / \mathrm{cm}^{3}$ & 1,91 & 1,91 & 1,91 & 1,91 \\
\hline Aşınma nispeti & $\%$ & 44 & 44 & 44 & 44 \\
\hline
\end{tabular}

Puzolanik malzemenin yüzey alanının yüksek olması mevcut yüzey alanı ile yükselme eğiliminde olması nedeniyle puzolanik malzeme, puzolanik çimentonun tepkimesini kolaylaştıracak ve basınç dayanımını ise yükseltecektir (Erdoğdu vd., 1999). Yapılan araştırmalar neticesinde mevcut kazanılan bulgular ile kıyaslandığında, Çolak (2003), doğal puzolanlar üzerine yaptığı bir araştırmada toplam $\mathrm{SiO}_{2}+\mathrm{Al}_{2} \mathrm{O}_{3}+\mathrm{Fe}_{2} \mathrm{O}_{3}\left(4564 \mathrm{~cm}^{2} / \mathrm{g}\right)$ miktarı $\%$ 80,6 olan bir malzemenin 28 ve 90 günlük kür süreleri için artarak azalan bir basınç dayanım sonuçlarına (sırasıyla, 4,45 ve 9,12 N/mm²) ulaşmıştır. Bu sonuç, araştırmacının kullandığı 
doğal puzolanik malzemenin içerdiği $\mathrm{Fe}_{2} \mathrm{O}_{3}$ miktarının (\%12,5) yüksek olmasından kaynaklandığı ön görülmektedir (Erdoğdu vd., 1999).

Çalışmada kullanılan klinker ve hazırlanan tüf katkılı puzolanik çimento örneklerinin fiziksel özellikleri (incelik, blaine ve özgül ağırlık) ile basınç dayanım test sonuçları Çizelge 7' de gösterilmiştir.

Çizelge 7. Puzolanik çimento örneklerinin fiziksel ve mekanik özelliklerinin karşılaştırılması.

Table 7. Comparison of physical and mechanical properties of pozzolanic cement samples.

\begin{tabular}{|c|c|c|c|c|c|c|c|c|c|c|c|}
\hline \multirow{2}{*}{ İçerik } & \multirow{2}{*}{ Birim } & \multirow{2}{*}{ Klinker } & \multicolumn{2}{|c|}{ TR1 } & \multicolumn{2}{|c|}{ TR2 } & \multicolumn{2}{|c|}{ TR3 } & \multicolumn{2}{|c|}{ TR4 } & \multirow{2}{*}{$\begin{array}{c}\text { TS197- } \\
1\end{array}$} \\
\hline & & & $\% 20$ & $\% 40$ & \%20 & $\% 40$ & $\% 20$ & $\% 40$ & \%20 & $\% 40$ & \\
\hline $\begin{array}{l}200 \mu \mathrm{m} \text { elek } \\
\text { üstü }\end{array}$ & $\%$ & 0,2 & 0,2 & 0,2 & 0,1 & 0,1 & 0,2 & 0,2 & 0,1 & 0,1 & \\
\hline $\begin{array}{l}90 \mu \mathrm{m} \text { elek } \\
\text { üstü }\end{array}$ & $\%$ & 1,6 & 0,3 & 0,6 & 0,3 & 0,7 & 0,4 & 0,7 & 0,2 & 0,5 & \\
\hline $\begin{array}{l}45 \mu \mathrm{m} \text { elek } \\
\text { üstü }\end{array}$ & $\%$ & 5,8 & 5,4 & 6,8 & 5,2 & 6,4 & 4,8 & 6,8 & 5,8 & 8,4 & \\
\hline $\begin{array}{l}\text { Özgül } \\
\text { yüzey, }\end{array}$ & $\mathrm{cm}^{2} / \mathrm{gr}$ & 3228 & 4167 & 4697 & 4232 & 4556 & 4140 & 4797 & 4524 & 4856 & $\geq 2800$ \\
\hline Yoğunluk & $\mathrm{gr} / \mathrm{cm}^{3}$ & 3,07 & 2,88 & 2,65 & 2,78 & 2,60 & 2,75 & 2,65 & 2,78 & 2,66 & \\
\hline $\begin{array}{l}\text { Hacim } \\
\text { genleşme }\end{array}$ & $\mathrm{mm}$ & 1 & 3 & 3 & 2 & 2 & 3 & 3 & 2 & 2 & $\leq 10$ \\
\hline $\begin{array}{l}\text { Priz başı- } \\
\text { Priz sonu }\end{array}$ & dakika & $\begin{array}{l}135- \\
220\end{array}$ & $\begin{array}{l}160- \\
290\end{array}$ & $\begin{array}{l}175- \\
290\end{array}$ & $\begin{array}{l}185- \\
300\end{array}$ & $\begin{array}{l}190- \\
305\end{array}$ & $\begin{array}{l}160- \\
290\end{array}$ & $\begin{array}{l}175- \\
290\end{array}$ & $\begin{array}{l}185- \\
300\end{array}$ & $\begin{array}{l}190- \\
305\end{array}$ & $\geq 75$ \\
\hline $\begin{array}{l}\text { 2. gün } \\
\text { dayanımı }\end{array}$ & $\mathrm{N} / \mathrm{mm}^{2}$ & 22,00 & 15,10 & 10,30 & 13,90 & 8,70 & 13,70 & 7,30 & 15,10 & 10,60 & $\geq 10$ \\
\hline $\begin{array}{l}\text { 7. gün } \\
\text { dayanımı }\end{array}$ & $\mathrm{N} / \mathrm{mm}^{2}$ & 36,30 & 27,90 & 20,00 & 26,30 & 18,60 & 25,90 & 15,60 & 27,30 & 21,90 & $\geq 21$ \\
\hline $\begin{array}{l}\text { 28. gün } \\
\text { dayanımı }\end{array}$ & $\mathrm{N} / \mathrm{mm}^{2}$ & 48,90 & 44,30 & 33,60 & 43,20 & 34,80 & 43,30 & 33,60 & 44,20 & 34,80 & $\geq 32,5$ \\
\hline
\end{tabular}

Puzolanik çimento örneklerinin basınç dayanım değerlerinin kullanılan tüf oranına ve kür zamanına bağıı olarak değişimleri sırası ile Şekil 3 ve Şekil 4'de verilmiştir. Çizelge 8'den de anlaşılacağı üzere değişik oranlarda kullanılan tüf (\%20-\%40) örnekleri ile üretilen puzolanik çimentoların kimyasal özellikleri TS EN 197-1, 2012'de açıklanan puzolanik çimento kriterlerine uymaktadır. 28 günlük kür süresi sonunda basınç dayanımları göz önüne alındığında Yozgat yöresi tüf örneklerinin, Cem II ve Cem IV/B puzolanik katkılı çimento üretiminde $\% 40$ 'a kadar kullanılabilir. Ancak $\pm \% 10$ puzolanik aktivite değişimleri göz önüne alındığında çimentoya en uygun \%15-40 oranında tüf olarak katılabileceğini söylenebilir (Şekil 3-4). 
Çizelge 8. TS EN 197-1:2012, Puzolanik çimento (Cem IV 32,5) özellikleri.

Table 8. TS EN 197-1: 2012, Properties of pozzolanic cement (Cem IV 32,5).

\begin{tabular}{|c|c|c|c|c|c|c|c|c|c|c|}
\hline \multirow[b]{3}{*}{$\begin{array}{c}\text { Ana } \\
\text { Tipler }\end{array}$} & \multicolumn{5}{|c|}{ Bileşim (Kütlece \% olarak) } & \multirow{3}{*}{$\begin{array}{c}\text { Dayanım } \\
\text { Sınıfı }\end{array}$} & \multicolumn{4}{|c|}{ Basınç Dayanımı (Mpa) } \\
\hline & \multicolumn{5}{|c|}{ Ana Bileşenler } & & \multicolumn{2}{|c|}{ Erken Dayanım } & \multirow{2}{*}{\multicolumn{2}{|c|}{\begin{tabular}{|c|}
$\begin{array}{c}\text { Nihai } \\
\text { Dayanım }\end{array}$ \\
28 \\
Günlük \\
\end{tabular}}} \\
\hline & \multicolumn{2}{|c|}{$\begin{array}{c}\text { Çimento Tipleri ve } \\
\text { Iş̧aretleri }\end{array}$} & \multirow{2}{*}{\begin{tabular}{c|} 
Klinker \\
$80-94$
\end{tabular}} & \multirow{2}{*}{\begin{tabular}{|c} 
Puzolan \\
$6-20$
\end{tabular}} & \multirow{2}{*}{\begin{tabular}{|c|}
$\begin{array}{c}\text { Minör } \\
\text { Ilave } \\
\text { Bileşen }\end{array}$ \\
$0-5$ \\
\end{tabular}} & & \multirow[t]{2}{*}{$\begin{array}{c}2 \\
\text { Günlük }\end{array}$} & \multirow{2}{*}{$\begin{array}{c}\begin{array}{c}7 \\
\text { Günlük }\end{array} \\
\geq 16,0\end{array}$} & & \\
\hline & Portlandlı & $\begin{array}{l}\text { Cem } \\
\text { II/A-P }\end{array}$ & & & & $32,5 \mathrm{~N}$ & & & & \\
\hline $\begin{array}{l}\text { Cem } \\
\text { II }\end{array}$ & $\begin{array}{l}\text { Puzolanlı } \\
\text { Çimento }\end{array}$ & $\begin{array}{l}\text { Cem } \\
\text { II/B-P }\end{array}$ & $65-79$ & $21-35$ & $0-5$ & 32 , & $\geq 10,0$ & & $\begin{array}{c}\geq \\
32,5\end{array}$ & $\begin{array}{c}\leq \\
52,5\end{array}$ \\
\hline & Portlandlı & $\begin{array}{l}\text { Cem } \\
\text { IV/A-P }\end{array}$ & $65-89$ & $11-35$ & $0-5$ & $42,5 \mathrm{~N}$ & $\geq 10,0$ & & & \\
\hline $\begin{array}{l}\text { Cem } \\
\text { IV }\end{array}$ & $\begin{array}{c}\text { Puzolanlı } \\
\text { Çimento }\end{array}$ & $\begin{array}{l}\text { Cem } \\
\text { IV/B-P }\end{array}$ & $45-64$ & $36-55$ & $0-5$ & $42,5 \mathrm{R}$ & $\geq 20,0$ & & $\begin{array}{c}\geq \\
42,5\end{array}$ & $\begin{array}{c}\leq \\
62,5\end{array}$ \\
\hline
\end{tabular}

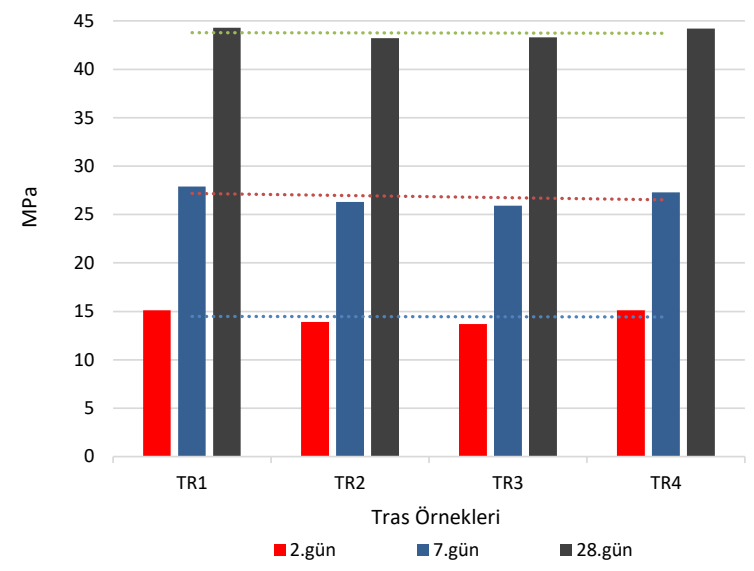

Şekil 3. Basınç dayanımının zamana bağlı olarak değişimi (\%20 Tüf Katkılı).

Figure 3. Time-dependent change of compressive strength (20\% tuff added).

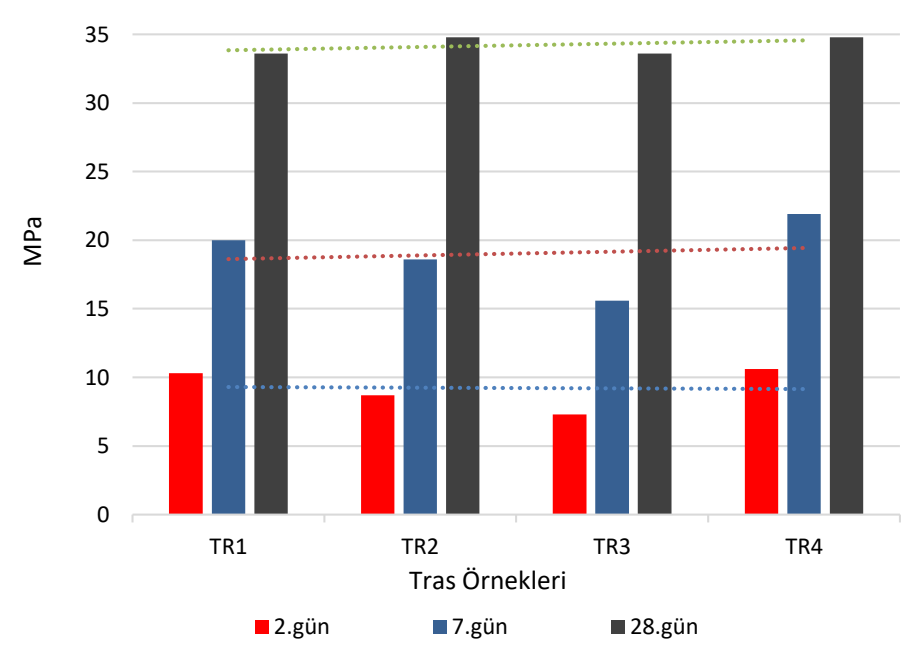

Şekil 4. Basınç dayanımının zamana bağıı olarak değişimi (\% 40 Tüf Katkılı).

Figure 4. Time-dependent change of compressive strength (40\% tuff additive).

Puzolanik çimento harçlarının basınç dayanımı test sonuçları incelendiğinde puzolan ilavesi arttıkça erken dayanımın giderek düştüğü görülmektedir. Deney süresinin 28 günle 
sınırlandırılmış olması ve doğal puzolanın henüz tamamen hidrate olmaması bu tür problemleri gündeme getirmektedir.

\section{SONUÇLAR}

Yozgat tüflerinin, volkanik orjinli bir porfirik traki-andezit olduğu ve toplam $\mathrm{SiO}_{2}+\mathrm{Al}_{2} \mathrm{O}_{3}+\mathrm{Fe}_{2} \mathrm{O}_{3}$ içeriklerinin \%77,97-\%83,62 arasında olduğu görülmüştür. Yozgat tüf örneklerinin kimyasal analiz sonuçları $\left(\mathrm{SiO}_{2}+\mathrm{Al}_{2} \mathrm{O}_{3}+\mathrm{Fe}_{2} \mathrm{O}_{3}\right.$ toplamı $\left.\geq 70\right)$ ve kireç ile yapılan puzolanik aktivite test sonuçları (7.gün basınç dayanımları 6,30 -10,70 MPa ve eğilmeden çekme 2,4-3,4 N/mm²), malzemenin TS 25/2015'te belirtilen doğal puzolan (tüf) gerekler ve uygunluk kriterlerini sağladığını göstermiştir.

Yozgat tüfü kompozit numunesinde mineralojik analiz (XRD) sonucunda, kuvars, feldspat cinsi SiO2 ve amorf yapı içeren bileşiklerin varlığı tespit edilmiştir. Örneklerin kısmen mikrolitik, çoğunlukla camsı olan hamur içinde albit ve kristobalit fenokristalleri içeren volkanik bir kayaç olduğu söylenebilir. Plajioklast fenokristalleri genellikle andezin içeriklidirler ve zonlu yapıdadırlar. Yapılan mikroskopik incelemeler malzemenin hyalomikrolitik porfirik dokuya sahip trakiandezit olarak tanımlanabileceğini göstermektedir.

Yozgat tüfü ile üretilen puzolanik çimento örneklerinde \%20 tüf katkısı ile her bir Yozgat tüf örneği için Cem II/B-P 32,5 R Portland puzolanik çimento ve Cem IV/B-P 32,5 R Portland puzolanik çimento kalite standartlarının üzerinde başarılı bir şekilde üretilmiştir. Üretilen \%40 tüf katkılı puzolanik çimentolarda TR 2 ve TR 3 Cem II/B-P 32,5 R Portland puzolanik çimento ve Cem IV/B-P 32,5 R Portland puzolanik çimento erken dayanım (2. Gün) değerleri TSE standartlarının altında kalmıştır. TR 2 ve TR 3 katkılarına kalker ilavesi ile Cem II ve Cem IV kompozit çimento üretimlerinin başarılı şekilde üretilebileceği ve kalite standartlarını yakalayabileceği ön görülmektedir.

Yozgat yöresi tüf örneklerinin \%40 ilavesiyle üretilen Puzolanik çimento örneklerinden TR1 ve TR4 ile Cem II/B-P 32,5 R Portland puzolanik çimento ve Cem IV/B-P 32,5 R Portland puzolanik çimento üretimleri başarılı bir şekilde gerçekleştirilmiştir. Puzolanik çimento erken ve geç dayanım değerleri TSE standartlarının üzerinde olduğu görülmüştür.

Yozgat yöresi doğal puzolan oranının \%40 gibi yüksek bir kullanım oranına çıkarılmasına rağmen puzolanlı çimento harçlarının TS EN 196'da belirtilen en düşük dayanım özelliğinin (32.5 N/mm²) üzerinde sonuç vermiş olmaları ve söz konusu asgari kriterleri güvenli bir şekilde sağlamış olması bir avantaj olarak değerlendirilmiştir. 
Yozgat'ta bulunan tüf ocakları, Yozgat çimento fabrikasına yaklaşık 55 km; Ankara'da bulunan çimento fabrikalarına yaklaşık $180 \mathrm{~km}$ ve komşu illerde bulunan çimento fabrikalarına ortalama 150 km uzaklığından dolayı getirdiği düşük nakliye masrafı açısından da avantajı bir konuma ve stratejik öneme sahiptir.

\section{KAYNAKLAR}

Alp, İ., Deveci, H., Yılmaz, A. O., Kesimal, A., Yılmaz, E., 2004. Taşhane (Terme) Andezitik Tüflerinin Çimento Üretiminde Katkı Maddesi Olarak Kullanılabilirliğinin Araştırılması. In: Proc. 5th Industrial Minerals Symp (Pp. 48-55).

Binici, H., 2002. PÇ-GYFC-Pomza Üçlü Karışımlarının Özellikleri. Doktora Tezi, Çukurova Üniversitesi Fen Bilimleri Enstitüsü, Adana.

Erdoğdu, K., Tokyay, M., Türker, P., 1999. Traslar ve Traslı Çimentolar. Türkiye Çimento Müstahsilleri Birliği, Arge, Ankara, 63 s.

Heikal, M., El-Didamony, E., Morsy. M. S., 2000. Limestone-filled Pozzolanic Cement. Cement and Concrete Research, 1827-1834.

Hewlett, P.C., 1998. Lea's Chemistry of Cement and Concrete. John Wiley and Sons Inc., Fourth Edition, New York, USA.

Kavas, T., Çelik, M. Y., 2001. Ayazini (Afyon) Tüflerinin Çimento Sanayiinde Tras Olarak Kullanılabilirliğinin İncelenmesi. Bilimsel Madencilik Dergisi, 40(4), 39-46.

Korkmaz, M., 1999. Terme Çamlıca Köyü Taşhane Mevkii Taş Ocağından Üretilen Malzemenin Çimento Hammaddesi Olarak Kullanılabilirliği. KTÜ, Maden Mühendisliği Bölümü, Bitirme Tezi, Trabzon, $102 \mathrm{~s}$.

Massazza, F., 1989. Pozzolanas and Durability of Concrete. Cement and Concrete World, $4,21,15-32$. 
Mesci, L,B., Gürsoy, H., 2002, Çobansaray-Karakaya (Yıldızeli HB-Sivas) arasındaki Orta Anadolu Bindirme Kuşağının (Kuzey Neotetis Kenedi) Tektonostratigrafik ve yapısal özellikleri. Cumhuriyet Üniversitesi Fen Bilimleri Dergisi,135-150.

Postacıoğlu, B., Çakıroğlu,N., Ortabası, N., 1960. Kayseri Puzolanları. İ.T.Ü Mimarlık Fakültesi, Yapı Araştırma Kurumu, Seri C, Sayı1, İstanbul.

Postacıoğlu, B., Uyan, M., Mazlum, F., 1987. Traslı Çimentoların Kullanma Alanları. i.T.Ü İnşaat Fakültesi, İstanbul.

TS-25, 1975. Tras, Türk Standartları Enstitüsü, Ankara

TS-24, 1985. Çimentoların Fiziki ve Mekanik Deney Metotları. Türk Standartlar Enstitüsü, Ankara.

TS-819, 1988. Rilem- Cembureau Standart Kumu. Türk Standartları Enstitüsü, Ankara.

TS EN 197-1, 2012. Genel Çimentolar, Genel Çimentolar- Bileşim, Özellikler ve Uygunluk Kriterleri. Türk Standartları Enstitüsü.

TS EN 197-2, 2012. Çimento, Uygunluk Değerlendirmesi. Türk Standartları Enstitüsü.

TS EN 196-1, 2012. Çimento Deney Metotları, Dayanım Tayini. Türk Standartları Enstitüsü.

TS EN 196-2, 2012. Çimento Deney Metotları, Çimentonun Kimyasal Analizi. Türk Standartları Enstitüsü.

TS EN 196-3, 2012. Çimento Deney Metotları, Priz Süresi ve Genleşme Tayini. Türk Standartları Enstitüsü.

TS EN 196-5, 2012. Çimento Deney Metotları, Puzolanik Çimentolarda Puzolanik Özellik Tayini. Türk Standartları Enstitüsü. 